\title{
Demographic transition in Sultanate of Oman: emerging demographic dividend and challenges
}

\author{
M. Mazharul Islam(1)
}

\begin{abstract}
Background: The sharp fall in fertility and mortality in Oman in recent time is quite stunning and more than expected, which is largely remained unexplored. This paper examined the characteristics of demographic changes and the emerging windows of opportunities and challenges for Oman. It also discussed the policy options. Data come from the national level surveys and censuses as well as the World Population Prospects 2019 Revision of the United Nations.

Results: The population of Oman grew from less than half a million in 1950 to more than four million in 2015, and expected to reach to seven million by 2055. After 1970, the annual growth rate of population accelerated due to increased immigration of working age population which has increased from less than $1 \%$ in 1970 to $44 \%$ in 2015 . The fertility rate has declined from 8.6 births per woman in 1988 to 3.3 births per woman in 2008, a decline of 5.3 births per woman or $62 \%$ decline within a short period of 20 years. Under-five mortality also declined from 359 deaths per 1000 live births in 1950 to nine deaths per 1000 live births in 2015. Demographic transitions leads to many changes in the size and age structure of the population in Oman that open up the opportunities of accruing demographic dividend for economic development of the country. The dependency ratio has decreased from 98\% in 1970 to 32\% in 2015. Two opening of demographic dividend period has been observed — first from 1958 to 2000 and the second one has opened in 2010 which will reach its peak during the 2020s and will remain open until 2040.
\end{abstract}

Conclusion: Oman has been experiencing a period of youth bulge over the years and it is expected to continue for at least next 20 years. To reap the benefits of the emerged demographic dividend, necessary steps need to be taken in a timely manner to develop human resources. Understanding the demographic challenges must be a priority for the government of Oman, and formulate policies to harvest the benefits of the demographic windows.

Keywords: Age structural transition, Demographic transition, Demographic dividend, Window of opportunity, Oman

\section{Background}

Change in the population size and structure is an inherent characteristic with every population. Demographers termed this change in population as "Demographic Transition." In general term, demographic transition refers to the movement of a population from a high birth and death rate to a low and stable level of birth and death rates [1-4]. In its classical form, demographic transition theory is essentially a description of the movement of the population that passes through various stages $[1,2,5]$. Demographic transition generates many demographic, social, and economic

Correspondence: mmazhar.islam@yahoo.com; mislam@squ.edu.om Department of Statistics, College of Science, Sultan Qaboos University, P.O. Box 36, 123, Al-Khoudh, Muscat, Sultanate of Oman opportunities as well as many social and policy challenges for the population [6-10]. The economic and social benefits derived from the demographic changes are termed by demographers as demographic "dividend" or "bonus" or "window of opportunity."

During the process of demographic transition, as the population move from high fertility and mortality state to low fertility and mortality state, there is an increase in the working age population as the huge number of children born during the previous high fertility period move into working ages and there is a decline in the child dependency ratio due to decline in fertility and mortality. As a result, fewer investments are needed for health and education of the children and the saved resources can be diverted to productive sectors [11-13]. A rapid economic growth is 
likely to occur if the country can transform the expanding working age population into human capital and utilize them properly. However, the emergence of the demographic dividend does not lead to economic development automatically. After emergence of demographic dividend, if a county cannot transform the expanding working age population into human capital and utilize that capital properly, the emerging demographic dividend can become a demographic burden for the country that may lead to socio-economic and political unrest $[14,15]$. Some demographers implicitly ascribed the recent demographic transition with rising "youth bulges" in the Arab world as a major cause of recent "Arab Spring" that have drawn attention to the importance of demographic factors in development as well as politics $[16,17]$.

Demographic transition can also create an inevitable "end-game" scenario. At the end of transition period, the relative size of the working age population begins to decline and the aged population starts to increase, leading to economic challenges. The reversal of the demographic window of opportunity and the aging of the working age population can be the factors contributing to an increase in the economic stagnation or recession that has been observed in many industrialized countries including Japan and could happen in many other countries in coming days [18].

The Sultanate of Oman - a country in the Arabian Peninsula with approximately 4.5 million people-is passing through a critical phase of demographic changes. Fertility is declining rapidly and the mortality rate has already reached to a low level of three deaths per 1000 populations in Oman [19-21]. Oman sees one of the fastest declines in fertility in a short period of time. A recent study by the American Enterprise Institute has cited Oman as one of the top five countries that have achieved more than five births decline per woman within just 20 years period [22].

Prior to the commercial exploitation of oil in late 1960s, the economy of Oman consisted of subsistence agriculture and fishing. However, the comprehensive modernization began in the country in early 1970s after the assumption of power by the late King His Majesty Sultan Qaboos bin Said Al-Said in 1970. By the late 1980s, Oman was transformed into a modern state, with all the modern facilities and infrastructures. The country is classified as high-income country by the World Bank.

The rapid demographic changes in Oman largely remained unexplored. To our knowledge, there is no study on this issue in Oman. Thus, the objective of this paper is to analyze the demographic transition in Oman and examine its implications on age structure of future population. The paper also focused on the emerging windows of opportunities and challenges due to age structural transition and discussed the policy option which would best grasp the windows of opportunities in Oman. While little is known on the demography of Oman, this paper is expected to contribute in expanding our knowledge about the demography of the country.

\section{Methods \\ The data}

Oman has very short history of demographic data. There was no census or survey in the country before 1980s. However, since 1988, a few national level population and health surveys were conducted by the Ministry of Health $(\mathrm{MoH})$. The 1988, Oman Child Health Survey provided the first national-level data on health and population [23], followed by the 1995 Oman Family Health Survey [24], the 2000 Oman National Health Survey [25], and the latest one is the 2008 Oman National Reproductive Health Survey [26]. This paper utilized data obtained from these national level surveys as well as censuses to describe the recent demographic changes in Oman. The latest country specific population projection data from the World Population Prospects 2019 Revision of the United Nations (UN) have also been used to describe the different aspects and consequences of past and future demographic transition in Oman [27].

The 2019 Revision of the United Nations population estimates and projections covered a 150-year time period, starting from 1950 to 2100, which is subdivided into past estimates (1950-2019) and future projections (2020-2100) [27]. However, this study considered past 70 years (1950-2019) estimates and future 50 years (2020-2070) projections results of medium variant of the 2019 Revision of the United Nations population projections.

\section{Analysis}

Various conventional demographic indicators have been used to analyze the population and age structural transition. The results are presented in tabular as well as graphical form. Age structural transition analysis has been done by following a typical life-cycle pattern that starts with childhood (age 0-14 years), a period of economic dependency during which consumption needs exceed labor income; followed by adulthood (age 15-64 years), a period of economic surplus during which labor income exceeds consumption needs; and then by retirement age $65+$ years), a period of economic dependency during which consumption needs again exceed labor income.

To assess the consequences of the age structural transition on the economy of the country, demographic dependency ratios and (economic) support ratios were calculated. The former indicator relates the dependent age groups (young people and the elderly) to the working-age population, whereas the later relates working age population to the total population [28]. This support ratio describes the relationship between the people who are supporting the whole economy and the consumption needs of all of the 
people in the economy. Microsoft Excel was used for calculating the demographic indices as well as for drawing graphs and diagrams. A brief description of the demographic rates and ratios used in the study are given below.

Crude birth rate (CBR), defined as the number of live births per 1000 mid-year population in a given year was calculated as $\mathrm{CBR}=\frac{\text { number of live births }}{\text { mid-year population }} \times 1000$. Similarly, the crude death rate (CDR), defined as the number of deaths per 1000 mid-year population in the given year was calculated as $\mathrm{CDR}=\frac{\text { number of live deaths }}{\text { mid-year population }} \times 1000$ [29].

The total fertility rate (TFR) refers to the average number of children that would be born alive to a woman during her lifetime if she were to pass through the childbearing years bearing children according to a current schedule of age-specific fertility rates. It was calculated as $\mathrm{TFR}=\sum\left(\frac{B_{x}}{P_{x}^{f}}\right)=\sum$ ASFR, where $B_{x}=$ number of live births to women aged $\mathrm{x}$ during a calendar year; $P_{x}^{f}=$ mid-year number of women at age $\mathrm{x}$, and ASFR $=$ agespecific fertility rate $=\frac{B_{x}}{P_{x}^{f}}$. When a 5 -year age group is employed, the sum of ASFR must be multiplied by 5 to calculate TFR [29].

To understand the magnitude of the emerging widow of opportunities in Oman, three types of demographic dependency ratios are calculated. Total dependency ratio (TDR) was calculated as the number of individuals aged $0-14$ years $\left(\mathrm{P}_{0-14}\right)$ plus individuals aged 65 years and over $\left(\mathrm{P}_{65+}\right)$ per 100 individuals aged 15-64 years $\left(\mathrm{P}_{15-64}\right)$ [30]. It indicates the relative predominance of persons in the "dependent" ages in relation to those in the productive ages as broadly defined in most social and economic systems. Thus $\mathrm{TDR}=\frac{\mathrm{P}_{0-14}+\mathrm{P}_{65+}}{\mathrm{P}_{15-64}} \times 100$. Similarly, child dependency ratio $(\mathrm{CDR})$ and elderly dependency ratio (EDR) were calculated as $\mathrm{CDR}=\frac{P_{0-14}}{P_{15-64}} \times 100$ and $E D R \frac{P_{65+}}{P_{15-64}} \times 10$ 0 , respectively [30].

Potential support ratio (PSR) is the number of individuals aged 15-64 per every individual aged 65 and over. Thus PSR $=\frac{P_{15-64}}{P_{65}}$. The aging index indicates the velocity of the aging process in a population. Aging index $=\frac{\mathrm{P}_{65+}}{\mathrm{P}_{0-14}}$ [30].

To analysis the time of opening and closer of demographic dividend, a simple algebraic model developed by Mason and Lee [31] has been used. The model is a simple algebraic identity that links income per capita $(\mathrm{Y} / \mathrm{N})$ to worker productivity (income per worker) (Y/L) and the worker support ratio (work force per capita $(\mathrm{L} / \mathrm{N})$ is as follows:

$$
\frac{Y(t)}{N(t)}=\frac{Y(t)}{L(t)} \times \frac{L(t)}{N(t)}
$$

where $Y(t)$ is the income at time $t, N(t)$ is the total population at time $t$, and $L(t)$ is the total number of workers at time $t$. By taking the natural log on both sides and then differentiating with respect to time, this expression can be converted from level to rate of growth as follows

$$
g_{y}=g_{x}+\left(g_{w}-g_{p}\right)
$$

where $g_{y}$ is the growth rate of per capita income, $g_{x}$ is the growth rate of income per worker, $g_{w}$ is the growth of worker, and $g_{p}$ is the growth rate of the total population. Thus $\left(g_{w}-g_{p}\right)$ is the rate of growth of the support ratio. The first dividend is then defined as the rate of growth of the support ratio.

\section{Results}

Population size and growth scenario of Oman

The demographic transition in Oman during the last 70 years consisted of two distinct period: 1950 to 1980 and 1980 onward (Fig. 1). The period 1950 to 1980 was characterized by a constant high level of fertility and a high but declining mortality rate. The period 1980 onward is characterized by declining fertility and mortality as well as declining natural growth rate, but fluctuating annual growth rate (Fig. 1). According to demographic transition theory, this stage may be termed as the third stage of demographic transition in Oman, which would like to continue until the middle of the twenty-first century.

The results presented in Table 1 reveal that the population of Oman grew from less than half a million in 1950 to 4.3 million in 2015; a gain of 3.8 million or nearly nine times as many people as were alive in 1950 . The first doubling of the population occurred in 1975 after 25 years from 1950 and a second doubling occurred in 1990, which took only 15 years from 1975. The shorter duration of second doubling was due to high population growth. The total population of Oman exceeded one million marks in 1980 and four million marks in 2015. The population of Oman will exceed five million by 2020 and it will reach to 7.1 million by 2055 (Table 1). Projection result indicates that after 2060, the population is likely to stabilize at 7.4 million.

During 1950s, the growth rate was below $2 \%$. The annual growth rate of the population increased from 1.66\% in 1950 to a very high rate of more than 5\% during $1980 \mathrm{~s}$ and all the time high rate of $6.7 \%$ in 2015 . Until 1970 , the population growth was mainly due to natural increase and the annual population growth rate was below 3\% (Fig. 1). After 1970, the annual population growth rate accelerated due to increasing rate of labor immigration. However, the annual growth rate of the population in Oman has never been uniform. After 1985, the growth rate started declining and it has reached to below $1 \%$ in 2000 , and then again started 


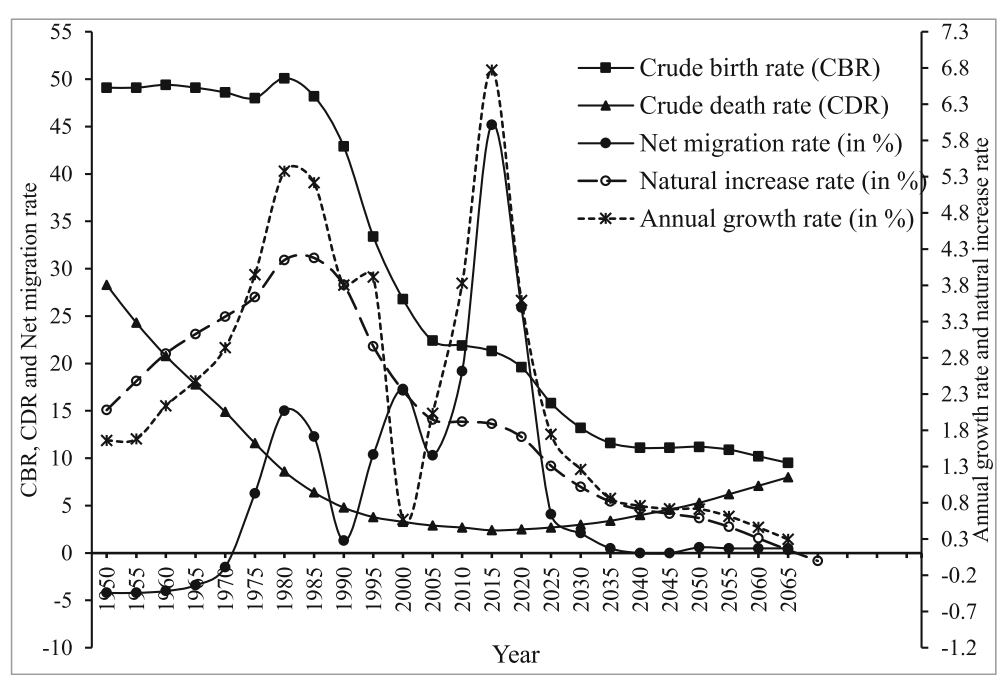

Fig. 1 Trends in annual population growth rate (in \%), rate of natural increase, crude birth rate (CBR), crude death rate (CDR), and net migration rate: Oman 1950-2065. Source: UN population estimates and projection [27]

rising. After 2010, the population growth rates started to decline due gradual decline in immigration rates as well as due to rapid fertility decline. However, the population growth rate will decline to $1.26 \%$ in 2030 and it will further decline to less than $1 \%$ (i.e., $0.5 \%$ ) in 2050 and the population may stabilize at around 7 million after 2060 .

\section{Changes in fertility, mortality, and migration - the drivers of demographic transition Mortality transition}

Like in the developed countries of Europe, demographic transition in Oman also began with a decline in mortality. The crude death rate (CDR) declined rapidly to about 3.0 deaths per 1000 populations in 2015 from a high rate of about 28.0 deaths per 1000 populations in 1950 (Fig. 2). The projection results, however, indicate slight increase in CDR after 2020, reaching to 8.5 deaths per 1000 populations in 2065. Like crude death rate, the infant mortality rate, which was around 211 deaths per 1000 live births in 1950, declined to about eight deaths per 1000 live births by the 2015, a decline of $96 \%$ over the last 65 years. Under-five mortality also declined from 359 deaths per 1000 live births in 1950 to nine deaths per 1000 live births in 2015 (Fig. 2). As a result of declining mortality, the life expectancy at birth has increased from a very low average of 36 years in 1950 to 77 years in 2015 in Oman (Fig. 2). The projection results indicate a continuous increase in life expectancy, reaching over 80 years in 2030 and further increase to 86 years in 2065.

\section{Fertility transition}

Rapid fall in fertility level over the last three decades played a major role in demographic transition in Oman.
Until 1980s, the fertility level in Oman remained almost constant at a high level of more than eight births per woman. Fertility started to decline rapidly during 1990s. The recent national level survey results demonstrate that the fertility rates have declined from a very high rate of 8.6 births per woman in 1988 to 3.3 births per woman in 2008, which is an unprecedented decline of 5.3 births per woman (or $62 \%$ decline) in just 20 years (Fig. 3). The crude birth rates (CBRs) also follow similar pace of decline over the period (Fig. 1).

The contraceptive prevalence rate (CPR) in Oman has increased from $8.6 \%$ in 1988 to $23.8 \%$ in 1995 , an increase of threefold (Fig. 3). The rate further increased to $31.7 \%$ in 2000, but has declined to $24.4 \%$ in 2008. The 2014 Multiple Indicator Cluster Survey (MICS) in Oman also reported a lower rate of CPR of $29.7 \%$ in 2014 than that observed in 2000. It is interesting to note that despite no improvement in the use of contraception in Oman since 2000, the total fertility rate is declining in Oman. This decline in TFR is mainly due to rapid rise in age at marriage in Oman.

There has been an appreciable rise in the proportion of single and fall in the proportion of currently married at early ages, particularly among females, indicating a rising trend in female age at marriage. For example, the proportion of single in age group 20-24 has increased from 13\% in 1988 to $55 \%$ in 2008, an increase of more than fourfold or 323\% between 1988 and 2008 (Fig. 4). As a result, the mean age at marriage for females has also increased from 19 years in 1988 to 27 years in 2008 (Fig. 4). Oman is likely to attain replacement level of fertility (i.e., a TFR of 2.1 ) by 2030 and after that it is expected to be stabilized at a rate below 2 . 
Table 1 Estimates and projections (medium variant) of total, male and female population size (in 1000), sex ratio, and annual growth rate of population: Oman 1950-2070

\begin{tabular}{|c|c|c|c|c|c|c|}
\hline \multirow{2}{*}{\multicolumn{2}{|c|}{ Year }} & \multicolumn{3}{|c|}{ Population size (in 1000) } & \multirow{2}{*}{$\begin{array}{l}\text { Sex } \\
\text { ratio }\end{array}$} & \multirow{2}{*}{$\begin{array}{c}\text { Annual growth } \\
\text { rate }(\%)\end{array}$} \\
\hline & & Both sex & Male & Female & & \\
\hline 19507 & & 456 & 225 & 232 & 103.11 & 1.66 \\
\hline 1955 & \multirow{4}{*}{$\begin{array}{l}\text { Doubled by } \\
25 \text { years }\end{array}$} & 496 & 248 & 248 & 100.00 & 1.68 \\
\hline 1960 & & 552 & 278 & 273 & 98.20 & 2.14 \\
\hline 1965 & & 625 & 318 & 307 & 96.54 & 2.48 \\
\hline 1970 & & 724 & 368 & 356 & 96.74 & 2.94 \\
\hline 1975 & \multirow{3}{*}{$\begin{array}{l}\text { Doubled by } \\
15 \text { years }\end{array}$} & 882 & 437 & 445 & 101.83 & 3.95 \\
\hline 1980 & & 1154 & 546 & 608 & 111.36 & 5.38 \\
\hline 1985 & & 1498 & 689 & 810 & 117.56 & 5.22 \\
\hline $1990-$ & \multirow{10}{*}{$\begin{array}{l}\text { Doubled by } \\
25 \text { years }\end{array}$} & 1812 & 803 & 1009 & 125.65 & 3.81 \\
\hline 1995 & & 2204 & 897 & 1307 & 145.71 & 3.92 \\
\hline 2000 & & 2268 & 995 & 1273 & 127.94 & 0.57 \\
\hline 2005 & & 2511 & 1091 & 1420 & 130.16 & 2.04 \\
\hline $2010=$ & & 3041 & 1207 & 1835 & 152.03 & 3.83 \\
\hline 2015 & & 4267 & 1484 & 2783 & 187.53 & 6.77 \\
\hline 2020 & & 5107 & 1736 & 3370 & 194.12 & 3.59 \\
\hline 2025 & & 5573 & 1933 & 3640 & 188.31 & 1.75 \\
\hline 2030 & & 5936 & 2103 & 3833 & 182.26 & 1.26 \\
\hline J & & 6197 & 2244 & 3953 & 176.16 & 0.86 \\
\hline 2040 & & 6437 & 2378 & 4059 & 170.69 & 0.76 \\
\hline 2045 & & 6672 & 2512 & 4160 & 165.61 & 0.72 \\
\hline 2050 & & 6915 & 2650 & 4266 & 160.98 & 0.72 \\
\hline 2055 & & 7131 & 2778 & 4353 & 156.70 & 0.62 \\
\hline 2060 & & 7298 & 2887 & 4411 & 152.79 & 0.46 \\
\hline 2065 & & 7407 & 2974 & 4434 & 149.09 & 0.30 \\
\hline 2070 & & 7463 & 3038 & 4425 & 145.66 & 0.15 \\
\hline
\end{tabular}

Source: UN population estimates and projection[27]

\section{Migration transition}

Like other oil-rich Arab Gulf countries, Oman started attracting huge foreign workforce after 1970. Figure 1 shows the trends in net migrated population in Oman. The data indicate that the proportion of net migrated population increased sharply since 1970 . The proportion of expatriate population has increased from less than $1 \%$ in 1970 to $44 \%$ in 2015. In general, Oman experienced a high rate of population increase due to large inflows of expatriate since 1970 (Fig. 1). Oman experienced a negative trend in net migration rate until 1970, indicating more out migration at that period (Fig. 1). After 1970, the net migration rate stated increasing with little fluctuations and reached to highest level of $45 \%$ in 2015 . The projection results also indicate a sharp decline in net migration rate after 2015, reaching to less than 1\% in 2035 .

\section{Age structural transition in Oman}

Demographic transition leads to many changes in age structure of a population which is called age-structural transition (AST). Change in age structure can efficiently be depicted graphically by the "population pyramids" or "age-sex pyramid." The broad-based triangular-shaped population pyramids of Oman for the period 1980-1990 indicate a typical population in an early stage of demographic development with relatively high birth rate and growth rates and a youthful population. The reduction in the mortality as well as fertility rates and increase in net migration caused a rapid transformation in the age structure between 1980 and 2015. During this period, the proportions of population under age 20 years showed gradual declining trends, while the proportions of population of age 20 years and above showed 


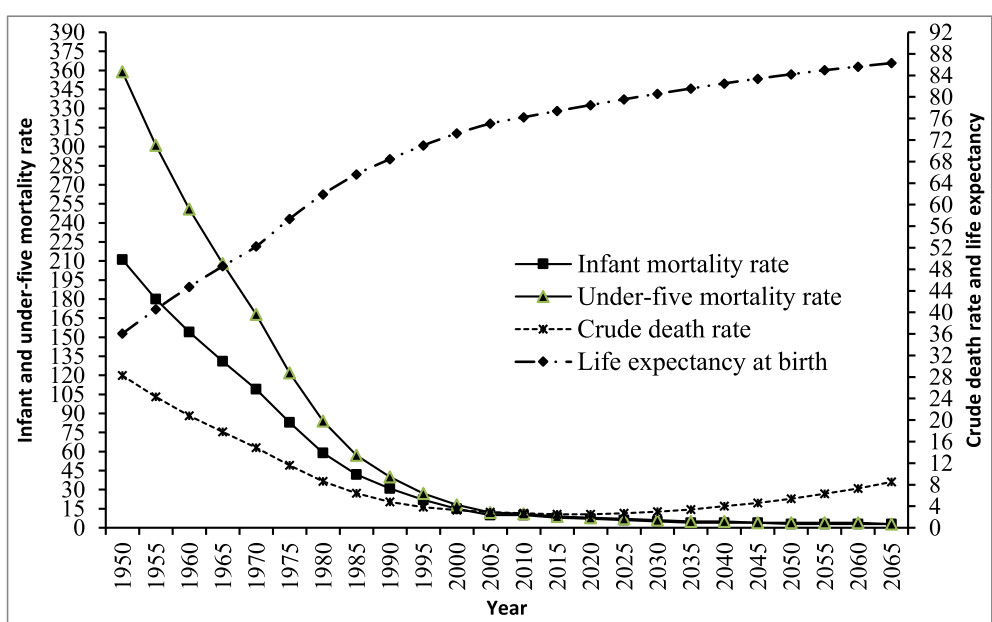

Fig. 2 Infant and under-five mortality rates, crude death rates and life expectancy at birth, Oman 1950-2065. Source: UN population estimates and projection [27]

increasing trends. The proportion of children under age five decreased from over $20 \%$ in 1980 to about 10\% in 2015 due to fall in fertility rate, which is reflected in the narrowed base of the pyramid in 2015. Similar pattern of reduction in the proportion of population has been observed in all other age groups under age 20 years during this period (Fig. 5). After 1980, the age structure of the population of Oman started to lose its regular pyramid shape due to huge increase in working age population of age 20-39 years of age.

The projection results indicate that the intensity of the change in age structure will further increase in the next five decades from 2020 to 2070. During this period, the base of the population pyramid will be slimming both in relative terms and in absolute numbers. As a result, the age structure will emerge as a beehive or barrel shape. Such a pyramid is typical of a population having low birth and death rates and a large proportion of the population surviving to working age and older ages.

The results indicate that since 1950 to 1990 , more than $40 \%$ of the total population was children under age 15 years. Due to decline in fertility in the late 1980s and onward, the relative share of the population of age less than 15 years began to decline, and it has declined from $45.3 \%$ in 1990 to $22.0 \%$ in 2015 . The proportionate share of the child population is expected to continue to declining further to reach to $15 \%$ by 2065 (Table 2). The relative share of prime working age population of age 25-49 years has increased from $24.0 \%$ in 1970 to more than $50 \%$ in 2000 and will reach to a peak of $56 \%$ in 2020, but will gradually decline to about 30\% in 2065 (Fig. 6).

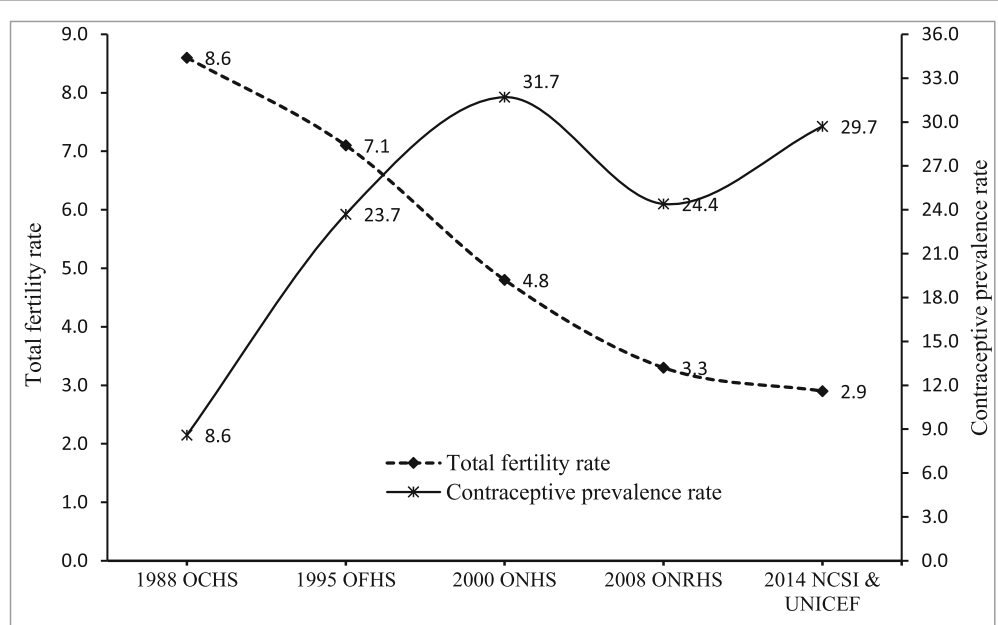

Fig. 3 Estimates of total fertility rates (TFRs) and contraceptive prevalence rates (CPRs) in Oman from different national level surveys between 1988 and 2014. Source: Sulaiman et al., [23, 24], Al-Riyami et al. [25, 26], NCSI \& UNICEF [32] 


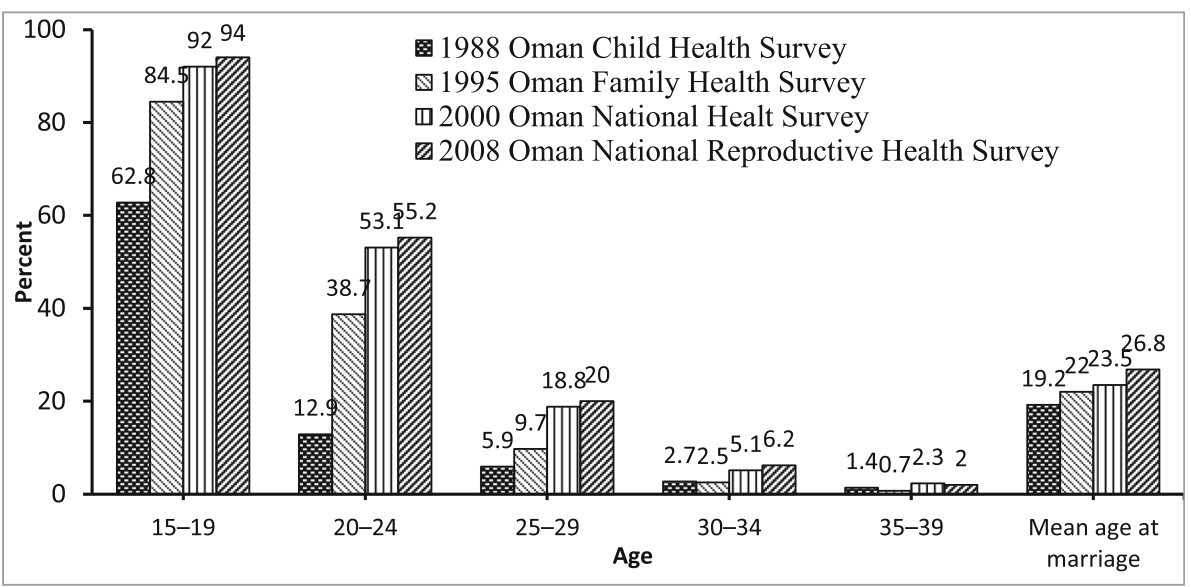

Fig. 4 Age-specific percentage of single women and mean age at marriage (SMAM) of women, 1988-2008. Source: Islam [21]

However, the absolute size of the prim working age population will continue to increase until 2065.

The proportional share of elderly population has been observed to be in the vicinity of $3 \%$ during the period 1950-2015 and it is expected to continue until 2025. However, after 2025, it will start increasing very fast. The proportion of the old age population will rise from $4.4 \%$ in 2030 to almost $22 \%$ in 2065 (Table 2).

\section{The emerging demographic dividend in Oman}

During demographic transition, there is a period when the proportion of people of potentially productive age or working age (15 to 64 years) grows steadily in relation to potentially dependent ages $(<15$ and $>64$ years). This situation is particularly conducive to the economy for any country and the period is termed as demographic dividend period. The ratios of economically dependent and economically active population groups are commonly used as indicators of the demographic dividend.

Table 3 presents the total dependency ratio and its components as well as the index of aging, calculated for the period 1950-2070. The results indicate that the burden of the economically dependent population continued to be very high during the period 1950 to 1990 . During this period, for every 100 economically active people, there are 83 to 98 economically dependent people in Oman, and more than $90 \%$ of those dependent populations are children under age 15 years, mainly due to high fertility rate. After 1990, the TDR started to decline mainly due to decline in the population of aged under 15 years (Fig. 7). This decline in TDR will continue until 2040, and after that it again start rising as a result of increasing elderly population. The aging index shows slight decline from about $7 \%$ in 1950 s to about 5\% in 1995 and then showed a monotonic increase. The aging index will rise to nearly $50 \%$ in 2040 , indicating that the number of elderly people will be half of the number of children under age 15 years (Fig. 7). The aging index is expected to increase to $104 \%$ in 2055 , implying that the number of elderly population will be close to the number of children under age 15 years. The index is expected to increase further to 163 in 2070, indicating that the number of elderly people will exceed the number of children under age 15 years.

Timings of opening and closure of demographic dividend The demographic dividend arises and gradually diminishes as changes in age structure interact with the life cycle of production and consumption. During the process of age structural transition, the first demographic dividend arises when the rate of growth of producers exceeds the rate of growth of consumers. The extent of first demographic dividend can be derived from the difference between the growth rates of working age population (15-64) $\left(g_{w}\right)$ and the growth rate of total population $\left(g_{p}\right)$ as given in equation (2). Figure 8 presents the extent of the estimated first demographic dividend in Oman (difference in the growth rate of producers and consumers).

Based on the trajectory of potential support ratio presented in Fig. 8, the expected years of opening and closing of demographic dividend and its duration can be ascertained. The results depicted in Fig. 8 revealed some interesting phenomenon of opening and duration of dividend period. There are two opening of the window of opportunity: first one opened in 1985 and closed in 2000, and second one opened in 2010 and the window is expected to be closed by 2040 , a period of about 30 years. The highest dividend (around $4 \%$ ) is expected to occur during the period 2015-2020 as the supply of working age population during this period will be higher. Of the per capita growth rate of income, $4 \%$ of the 

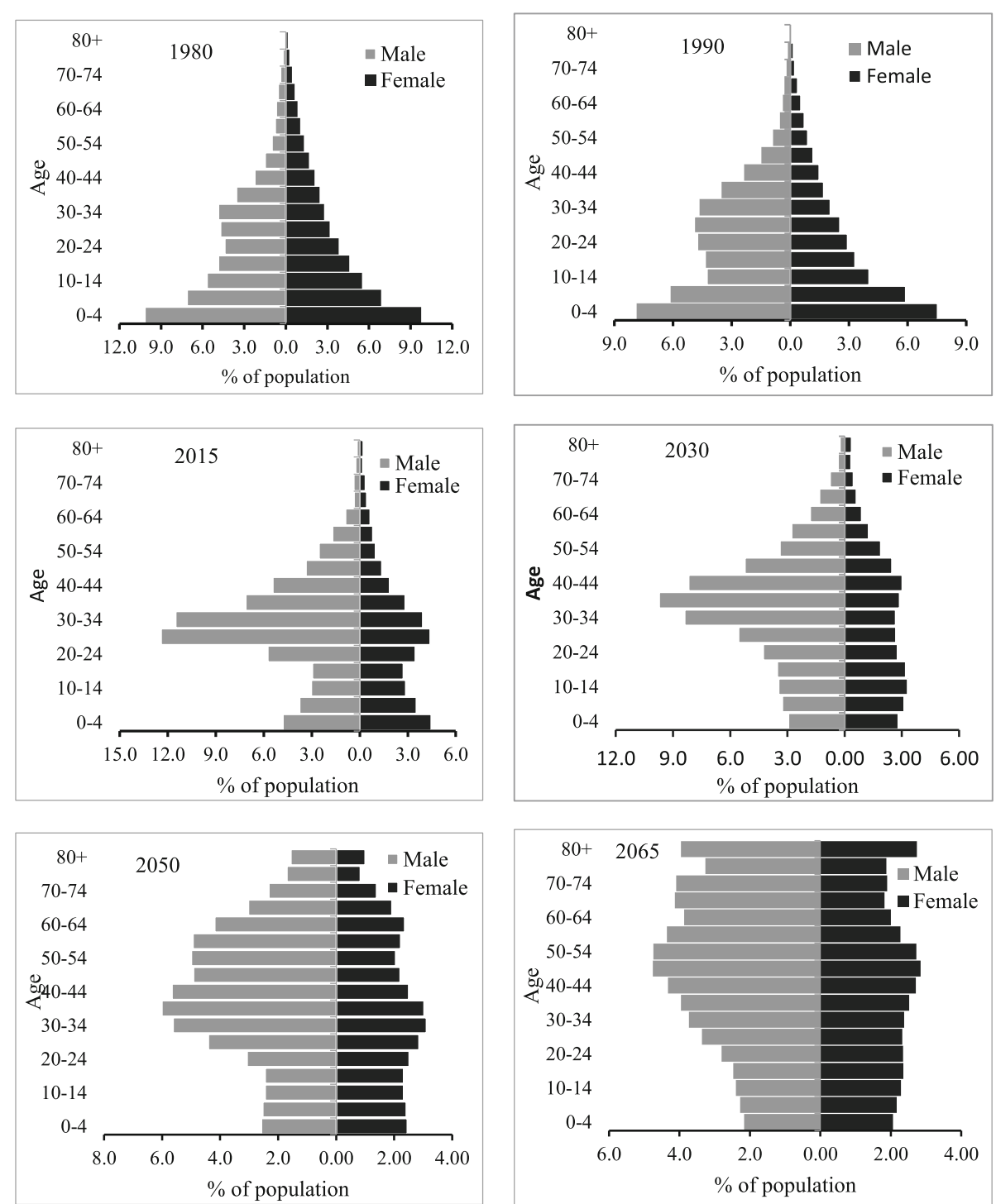

Fig. 5 Population pyramid, Oman, 1980-2065. Source: UN population estimates and projection [27]

growth rate is likely to be contributed by the labor supply alone during this period.

\section{The emerging challenges for Oman}

As a result of past high levels of fertility and increasing level of age-selective in migration along with steep decline in mortality, the growth rate of population has been accelerated in Oman. This has increased and will put more pressure on the demand for food, education, healthcare, housing, and jobs. Due to demographic transition, Oman has been experiencing a period of youth bulge over the years and is expected to face many challenges for the next 15 to 20 years in meeting the needs and services of this huge youth bulge, especially in providing quality education, good training, and creating job opportunities. In Oman, the working age population (15-64) was about 0.6 million in 1980 which has increased to 3.2 million in 2015. By 2050, an additional 1.7 million working age population will be added, giving rise a total of 4.9 million working age people in 2050 (Table 2). This huge increase of about 1.7 million people in the labor force between 2015 and 2050 is creating and will continue to create heavy pressure on the country's job markets. Currently (during 2015-2019), there are 3.2 million people in working age which is about $70 \%$ of the total population, and approximately 151,000 people are joining in working age per year (Table 2). However, the increasing trends of working age population will start to decline after 2040. 
Table 2 Estimates and projections (medium variant) of percentage of population by broad age groups in Oman: 19502070

\begin{tabular}{|c|c|c|c|c|c|}
\hline \multirow[t]{2}{*}{ Year } & \multicolumn{5}{|c|}{$\%$ of population by broad age group } \\
\hline & $0-14$ & $15-24$ & $25-64$ & $15-64$ & $65+$ \\
\hline 1950 & 42.3 & 19.1 & 35.5 & 54.6 & 3.1 \\
\hline 1955 & 42.9 & 19.4 & 35.3 & 54.6 & 3.0 \\
\hline 1960 & 43.7 & 19.4 & 33.9 & 53.3 & 2.9 \\
\hline 1965 & 45.0 & 19.0 & 32.8 & 51.8 & 3.2 \\
\hline 1970 & 46.3 & 18.5 & 31.9 & 50.4 & 3.0 \\
\hline 1975 & 45.8 & 18.4 & 32.8 & 51.1 & 2.9 \\
\hline 1980 & 45.1 & 17.7 & 34.7 & 52.3 & 2.8 \\
\hline 1985 & 45.6 & 16.4 & 35.5 & 51.9 & 2.4 \\
\hline 1990 & 45.3 & 15.9 & 36.5 & 52.4 & 2.3 \\
\hline 1995 & 39.6 & 16.0 & 42.4 & 58.4 & 2.1 \\
\hline 2000 & 37.1 & 21.4 & 39.1 & 60.5 & 2.5 \\
\hline 2005 & 32.5 & 22.0 & 42.9 & 64.9 & 2.5 \\
\hline 2010 & 25.7 & 21.1 & 50.5 & 71.7 & 2.7 \\
\hline 2015 & 21.8 & 14.7 & 61.3 & 75.9 & 2.3 \\
\hline 2020 & 22.5 & 10.7 & 64.4 & 75.0 & 2.5 \\
\hline 2025 & 22.5 & 11.9 & 62.4 & 74.2 & 3.3 \\
\hline 2030 & 21.1 & 13.7 & 60.8 & 74.4 & 4.4 \\
\hline 2035 & 18.6 & 14.8 & 60.7 & 75.5 & 5.9 \\
\hline 2040 & 16.8 & 14.7 & 60.5 & 75.2 & 8.0 \\
\hline 2045 & 16.0 & 12.9 & 60.6 & 73.5 & 10.6 \\
\hline 2050 & 15.8 & 11.1 & 60.2 & 71.3 & 12.8 \\
\hline 2055 & 15.8 & 10.4 & 57.3 & 67.7 & 16.5 \\
\hline 2060 & 15.5 & 10.3 & 54.1 & 64.5 & 20.0 \\
\hline 2065 & 14.9 & 10.6 & 53.0 & 63.5 & 21.6 \\
\hline 2070 & 14.1 & 10.7 & 52.2 & 62.9 & 23.0 \\
\hline
\end{tabular}

Source: UN population estimates and projection [27]

Demographic transition also stimulates internal (rural to urban) migration due to increase in population pressure. According to the 2010 population and housing census in Oman, two-third (75\%) of the total population was living in the urban area. In recent years, most of the cities in Oman are experiencing rapid population growth. While the annual population growth rate in the country is less than $2 \%$ per annum at the national level in recent time, it is more than $5 \%$ in most of the big cities, and it is expected that more than $80 \%$ of the population of Oman will live in urban areas by the year 2025 and almost $90 \%$ by 2050 [33]. Thus, the urban population is increasing rapidly with the increase in workingage population and Oman will have to face the challenge of rapid urbanization.

The growing size and share of the elderly population of age 65 years and above is emerging as another serious challenge for Oman economy. At present, a small proportion of about $2.5 \%$ of the total population are elderly persons. The elderly population of Oman would increase from 98,000 in 2015 to 888,000 in 2050 and to $1,599,000$ by 2065 (Table 2). By 2050, the share of elderly population would represent $13 \%$ of the total population and by 2065 almost $22 \%$. Thus, Oman is likely to face the challenge of the complexity of aged society by 2050 .

\section{Discussion}

Oman is passing through a crucial phase of demographic transition which has occurred following the classic demographic transition theory that fertility decline follows the mortality decline. For example, under-five mortality has declined from 359 deaths per 1000 live births in 1950 to nine deaths per 1000 live births in 2015. On the other hand, fertility has declined profoundly, from a natural level of fertility with nearly nine births per woman in the late 1980s to a controlled level of fertility with about three births per woman in the early 2000s. The decline in fertility and mortality in Oman can be attributed to the massive socio-economic development and government's policy measures that resulted many changes in the reproductive behavior and lifestyles of women, improved living conditions, urbanization, educational development, and development of modern health care system $[17,21]$. The decline in mortality in Oman and other Gulf countries has gone hand in hand with a series of processes collectively known as socio-economic and "epidemiological transition," the main feature of which is a change in the prevalence of certain diseases and causes of death [17, 34]. Though later than Europe and America, demographic change in other Muslim countries, including the Arabian Gulf countries, is a recent common phenomenon. One recent study described the contemporary demographic changes in the Muslim world as " a veritable sea-change, still curiously unnoticed" [22]. Like Oman, sharp fertility declines have been noticed in many other Arab countries, such as in Algeria and Libya, where fertility fell by five children, from more than seven children per woman in 19701975 to less than three children per woman in 20052010 [35]. In other Gulf countries, fertility has declined by at least $50 \%$ between 1970 and 2010 [35].

Demographic transition has created many changes in the age structure of the population in Oman. The size and relative share of the child population under age 15 is declining. On the other hand, the size and share of the population of youth (age 15-24), prime working age (25-49), and mature working age (50-64) is increasing. As a result, there is a declining trend in the dependency ratio in Oman, which is very important for its economic development process. The current and future decline in the dependency ratios would increase the working age 
Table 3 Dependency ratios, relative share of child and elderly dependency ratio, and aging index in Oman, 1950-2070

\begin{tabular}{|c|c|c|c|c|c|c|c|}
\hline \multirow[t]{2}{*}{ Period } & \multicolumn{3}{|c|}{ Dependency ratios (\%) } & \multicolumn{3}{|c|}{ Relative share of } & \multirow{2}{*}{$\begin{array}{l}\text { Aging index } \\
(\%)^{d}\end{array}$} \\
\hline & $\mathrm{TDR}^{\mathrm{a}}$ & $\mathrm{CDR}^{\mathrm{b}}$ & $\mathrm{EDR}^{\mathrm{C}}$ & $\overline{C D R}$ & EDR & Total & \\
\hline 1950 & 83.1 & 77.5 & 5.6 & 93.2 & 6.8 & 100.0 & 7.3 \\
\hline 1955 & 84.1 & 78.6 & 5.5 & 93.4 & 6.6 & 100.0 & 7.0 \\
\hline 1960 & 87.4 & 82.0 & 5.4 & 93.8 & 6.2 & 100.0 & 6.6 \\
\hline 1965 & 92.9 & 86.7 & 6.2 & 93.4 & 6.6 & 100.0 & 7.1 \\
\hline 1970 & 97.8 & 91.8 & 6.0 & 93.8 & 6.2 & 100.0 & 6.6 \\
\hline 1975 & 95.3 & 89.6 & 5.8 & 94.0 & 6.0 & 100.0 & 6.4 \\
\hline 1980 & 91.4 & 86.1 & 5.3 & 94.2 & 5.8 & 100.0 & 6.2 \\
\hline 1985 & 92.4 & 87.8 & 4.6 & 95.0 & 5.0 & 100.0 & 5.3 \\
\hline 1990 & 90.7 & 86.3 & 4.4 & 95.1 & 4.9 & 100.0 & 5.1 \\
\hline 1995 & 71.4 & 67.8 & 3.6 & 95.0 & 5.0 & 100.0 & 5.3 \\
\hline 2000 & 65.3 & 61.3 & 4.1 & 93.8 & 6.2 & 100.0 & 6.7 \\
\hline 2005 & 54.0 & 50.1 & 3.9 & 92.7 & 7.3 & 100.0 & 7.8 \\
\hline 2010 & 39.6 & 35.9 & 3.7 & 90.6 & 9.4 & 100.0 & 10.4 \\
\hline 2015 & 31.8 & 28.8 & 3.0 & 90.5 & 9.5 & 100.0 & 10.5 \\
\hline 2020 & 33.3 & 30.0 & 3.3 & 90.0 & 10.0 & 100.0 & 11.1 \\
\hline 2025 & 34.7 & 30.3 & 4.4 & 87.3 & 12.7 & 100.0 & 14.5 \\
\hline 2030 & 34.3 & 28.4 & 5.9 & 82.8 & 17.2 & 100.0 & 20.8 \\
\hline 2035 & 32.4 & 24.6 & 7.8 & 75.8 & 24.2 & 100.0 & 31.9 \\
\hline 2040 & 32.9 & 22.3 & 10.6 & 67.7 & 32.3 & 100.0 & 47.6 \\
\hline 2045 & 36.2 & 21.7 & 14.4 & 60.1 & 39.9 & 100.0 & 66.5 \\
\hline 2050 & 40.2 & 22.2 & 18.0 & 55.2 & 44.8 & 100.0 & 81.2 \\
\hline 2055 & 47.7 & 23.4 & 24.4 & 49.0 & 51.0 & 100.0 & 104.3 \\
\hline 2060 & 55.1 & 24.0 & 31.1 & 43.6 & 56.4 & 100.0 & 129.2 \\
\hline 2065 & 57.4 & 23.4 & 34.0 & 40.8 & 59.2 & 100.0 & 145.2 \\
\hline 2070 & 58.9 & 22.4 & 36.5 & 38.1 & 61.9 & 100.0 & 162.8 \\
\hline
\end{tabular}

${ }^{a}$ Children dependency ratio $(C D R)=$ population aged less than $15 /$ population aged 15-64

${ }^{\mathrm{b}}$ Elderly dependency ratio $(E D R)=$ population aged 65 or more $/$ population aged 15-64

${ }^{\prime}$ Total dependency ratio $(\mathrm{TDR})=\mathrm{CDR}+\mathrm{EDR}$

${ }^{\mathrm{d}}$ Aging Index = population aged 65 or above / population aged less than 15

population and their participation in labor force in Oman. The increased participation of people in the labor force leads directly to increased saving at the household and macro levels, and the saved resources can be diverted to productive sectors. It brings opportunities for families to invest more on education, nutrition, and health of their children, which in turn enhance the quality of human capital in the country. The increased employment also leads to numerous indirect benefits, such as increase in savings and investment, infrastructure development, and institution building $[11,12,14]$. There is increasing evidence that improvements in early childhood health and nutrition lead to improved educational outcomes and labor market productivity [36].
Demographic transition in Oman would also enhance women's participation in labor force, as family size becoming smaller due to reduction in fertility. There is also emerging evidence of causal effects of reduction in fertility on investments in children [37]. During the period of window of opportunity, the size and share of the female labor force also increases. Demographic transition does not only affect the family size but also the reproductive life span of women and their social status. It reduces the number of children per woman, increases her reproduction free life, and provides opportunity to improve her level of education. As a result, more women become able and often more willing to participate in workforce for cash earning, and are more likely to invest additional income to education and health of their children. Oman has already been receiving economic benefits by employing large number of female workers in different non-manufacturing public sectors. Oman would likely to have added demographic dividend by creating employment for women, and increasing female labor force participation rate in both service and manufacturing sectors.

Oman has been experiencing a period of youth bulge over the years and it is expected to continue for at least next 20 years. The increasing working age population, especially the population of prime age workers (age 2549) would result in greater capital accumulation, because, according to consumer behavior model, prime aged workers tend to save more, while younger worker (15 to 24$)$ tend to consume and borrow [38, 39]. Prime age workers are also more productive relative to younger workers and thus likely to earn higher incomes [9].

The increase in size of working age population opens up both opportunity and many challenges for the country. Challenges are to provide education, training, health care, and housing and create employment opportunities for the increased youth bulge, while opportunity is the positive impact on economy. Oman could be benefited from its rapid growth of workforce by speedy increasing employment opportunities to match the growth in labor supply. Failure to do so will bring many negative consequences like increased unemployment rate, crime rate, and social and political unrest.

Over the period, the size and share of the elderly population would increase in Oman due to demographic transition and increase in life expectancy. As a result, Oman would have to face the challenges of health care, retirement benefits, and social services for a huge number of elderly populations. To meet the challenges, Oman would need to allocate resources to address at least three fundamental need of the elderly population, which include social security, pension, health, and participation in income-generating activities. As this would also be the period of second demographic dividend, policies aimed at providing incentives to 


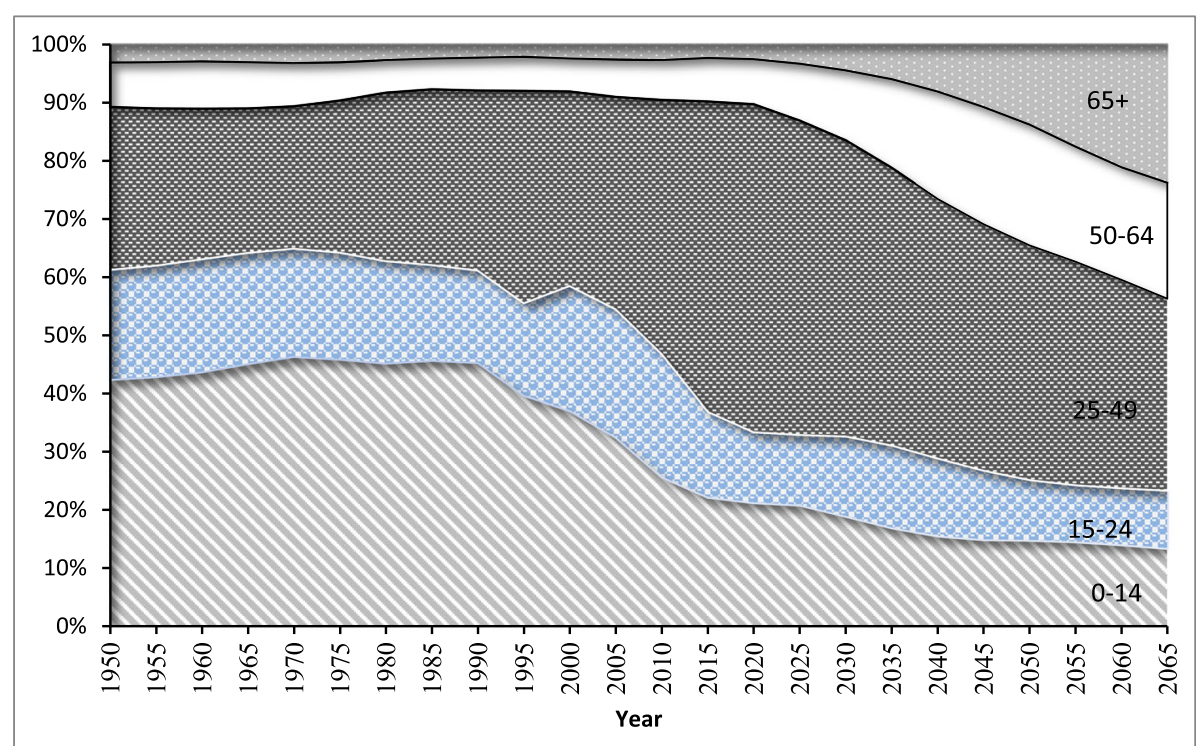

Fig. 6 Age structural transition in Oman 1950-2065. Source: UN population estimates and projection [27]

save and accumulate wealth during this phase are important components to optimally utilize this opportunity.

It is worth mentioning here that we have observed two opening of demographic dividend period in Oman-first from 1958 to 2000 and the second one has opened in 2010 which will reach its peak during the 2020s and will remain open until 2040. This type of multiple opening of demographic dividend has also been observed by Saxena [40] in some other Arab countries with high immigration of age selective workers. However, this phenomenon of multiple opening of demographic dividend is rare in demographic literature, and incompatible with the observation made by Lee and Mason [41] that "demographic dividend is onetime opportunity during a complete cycle of demographic transition." The opening of only one time demographic dividend might be true with the populations where international migration is not a big issue. The phenomenon of multiple openings of demographic window can occur in countries having relatively small native populations but comparatively high international migration (age-selective emigration and immigration). In Oman, the influx of working age labor force started during early 1980s that increased the growth of support ratio at that time and thus opened the demographic window. However, the disruption of supply of working age population during the 1990s due to Middle East crisis as well as the continued high fertility at that time reduced the support ratio and the demographic dividend period collapsed soon.

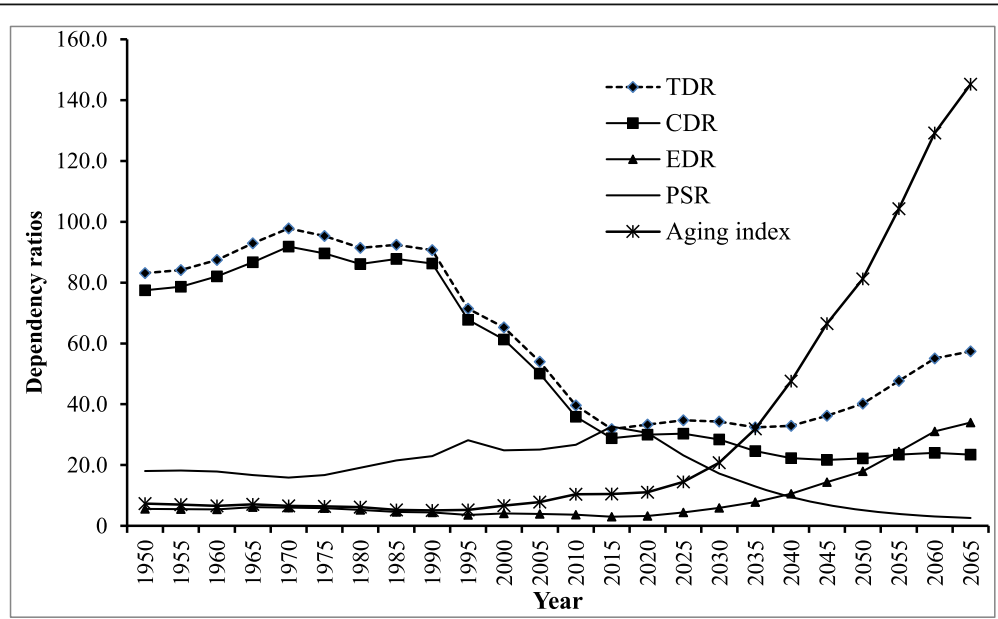

Fig. 7 Dependency ratios, potential support ratio and aging index, 1950-2065. Source: UN population estimates and projection [27] 


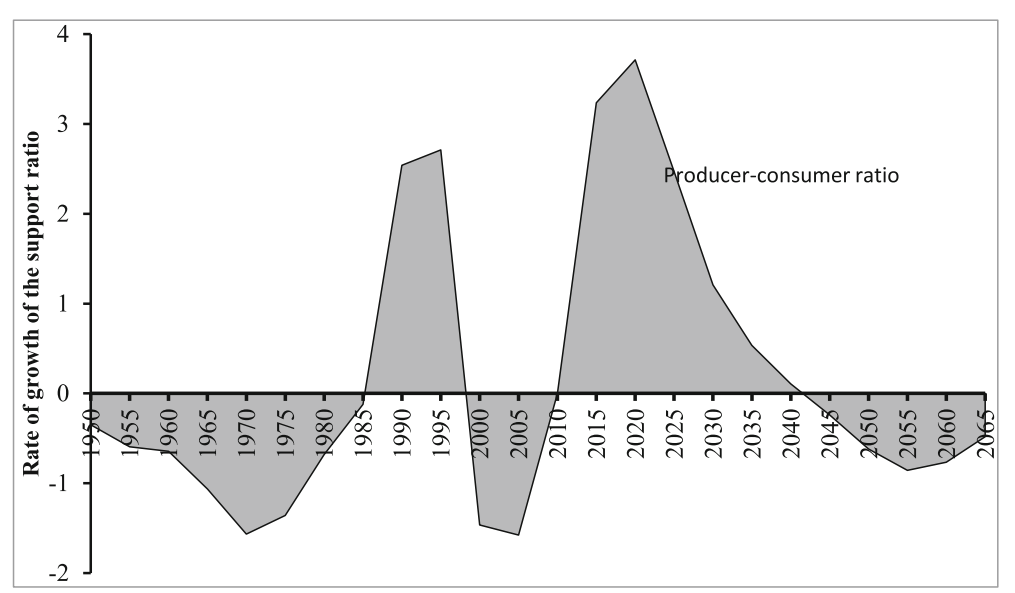

Fig. 8 Estimated period of demographic dividend in Oman. Source: UN population estimates and projection [27]

For any population, the period of demographic dividend is transient and would not last forever. The windows of opportunities that have emerged in Oman will not last long and will not be repeated within a short period. Oman government need to be careful about how to capitalize the various opportunities of demographic transition. The policymakers should act soon to formulate and implement appropriate policies to accelerate the demographic transition and to reap the economic benefits from the widow of opportunity provided by demographic transition. Investment in health is also important to ensure that the working population is healthy and productive. Realizing the demographic dividend and adopting appropriate policies, Oman has the potential to emerge as a prosperous country. A failure to act properly could have a damaging effect on future prospects turning the country to destine to face "Malthusian trap."

To reap the demographic dividend by making effective management of the demographic window of opportunities, Oman need to focus on quality education, job creation, and employment of the increased working age population. It also needs health care development and policies for the development of infrastructure for socio-economic development. This has already been proved by the East Asian countries that an effective management of window of opportunity can convert a population explosion to a population bonus and thus can be a factor for the rapid economic growth and development. As Bloom and Williamson [6] observed that in many East Asian countries, demographic transition contributed substantially to East Asia's so-called economic miracle and such miracle occurred because "East Asian countries had social, economic, and political institutions and policies that allowed them to realize the growth potential created by transition."

Over the period, Oman has achieved remarkable success in increasing the net enrolment rate in primary schools which is close to universal and achieved gender parity in school enrolment. Currently, about 40,000 Omani pass the secondary level of education or general education diploma in each year, of which $90 \%$ get admitted into higher educational institutes, and approximately 25,000 graduated annually [19]. This indicates that at least 25,000 jobs have to be created for the graduates per year.

Despite decades of economic expansion, extensive investments in infrastructure development, and economic diversification, youth unemployment persist in Oman to some extent. According to a recent report of World Economic Forum [42] on youth unemployment in Gulf countries, about $21 \%$ youth in Oman, who are mostly graduated with tertiary level of education, are unemployed, although the overall unemployment rate is around $8 \%$ in the country. The report also demonstrated a significantly higher rate of unemployment among females than males ( $31 \%$ vs. $18 \%$ ).

The youth-graduate unemployment problem in the country may be attributed to the mismatch between the skills demanded by employers and the skills offered by the labor force. Despite there exist large number of graduates in recent time, there is a shortage of skilled labor force with certain specialization. Graduate unemployment remains high despite a labor market desperately looking out for skilled workers. This apparent paradox can be explained in part by the fact that the country's education systems are not producing graduates with the skills needed by the labor market. There are social and economic reasons why youth unemployment remains so high in Oman and other Gulf countries. There is preference among nationals in Oman and other Gulf countries to work in the public sectors, because it brings a certain amount of prestige as well as lifetime job security with pensions, and health care. Further, because many public sector jobs are not demanding, some lower level civil servants can moonlight by taking on a second job to earn extra income for their families. 


\section{Conclusions}

Demographic transition in Oman has created many important changes in population age structure and opened the window of opportunities for economic development due to rising share of working age population. In Oman, one short period of opportunity (1985-2000) has already gone and another one has opened in 2010 and it is expected that it will continue until 2040. Policymakers should consider the interrelationships between population structure and potential opportunities for economic growth and development. In order to reap the benefits of the emerging demographic dividend, Oman has to take necessary steps in timely manner to address the need of the growing population. Understanding demographic challenges must therefore be a priority for the government of Oman, and formulate policies to harvest the benefits of the demographic windows.

\section{Abbreviations}

CDR: Crude death rate or child dependency ratio; CPR: Contraceptive prevalence rate; DHS: Demographic and Health Survey; EDR: Elderly dependency ratio; MoH: Ministry of Health; NCSI: National Centre for Statistics and Information; TDR: Total dependency ratio; TFR: Total fertility rate; UN: United Nations

\section{Acknowledgments}

The author is thankful to the Ministry of Health of Oman and the UN Population Division for making the necessary data available. Thanks are also due to anonymous reviewers and the Associate Editor for their insightful comments and suggestions that help improve the quality of this research paper. The views expressed herein are solely those of the author and do not necessarily reflect the views of any institution or organization.

\section{Authors' contributions}

The corresponding author is the sole author of this study, who conceive this study, gathered data, analyzed data, and wrote the manuscript. The author read and approved the final manuscript.

\section{Funding}

This research received no grant from any organization.

\section{Availability of data and materials}

The data sets used from the national level surveys and census could not be shared because of policy of Omani Government. However, the data set used from the 2019 Revision of the World Population Prospects produced by the United Nations Population Division is available at http://population.un.org/wpp.

\section{Ethics approval and consent to participate}

This study is based on secondary analysis of the data from different national level surveys and census in Oman. All study participants gave informed consent before participation in the survey and census and all information was collected confidentially. The study also utilized publicly available dataset of the 2019 Revision of the World Population Prospects produced by the United Nations Population Division. As such the study did not need any ethical approval.

\section{Consent for publication}

Not applicable.

\section{Competing interests}

The author declares that he has no competing interest.
Received: 24 October 2019 Accepted: 10 February 2020

Published online: 18 February 2020

\section{References}

1. Thompson WS (1930) Population Problems. McGraw- Hill, New York

2. Kirk D (1996) Demographic transition theory. Popul Stud 50:361-387

3. Lee R (2003) The demographic transition: Three centuries of fundamental change. Journal of Economic perspectives 17(4):167-190

4. Notestein F (1953) Economic problems of population change. In: Proceedings of the Eight International Conference of Agricultural Economics. Oxford University Press, London

5. Davis K (1945) The world demographic transition. Ann Am Acad Pol Soc Sci 237(1):1-11

6. Bloom DE, Williamson J (1998) Demographic transitions and economic miracles in emerging Asia. World Bank Econ Rev 12:419-456

7. Pool, I., Wong, L.R. \& Vilquin, E. (2006). Age-structural transitions: challenges for development. Committee for International Cooperation in National Research in Demography (CICRED), Paris.

8. Mason A, Lee R (2006) Reform and support systems for the elderly in developing countries: capturing the second demographic dividend. Genus 62(2): 11-35

9. Gomez R, deCos PH (2008) The importance of being mature: the effect of demographic ageing on global per-capita GDP. J Popul Econ 21(3):589-608

10. Spoorenberg $T$ (2008) The demographic window, development and population policy implications in Mongolia. Asian Popul Stud 4(2):215-232

11. Bloom DE, Canning D, Sevilla J (2003) The demographic dividend: a new perspectives on the economic consequences of population change. Rand, Santa Monica

12. Pool I (2007) Demographic dividends: determinants of development or merely windows of opportunity? Ageing Horizons 7:28-35

13. Mason A, Kinugasa T (2008) East Asian economic development: two demographic dividend. J Asian Econ 19:389-399

14. Mason A (2007) Demographic transition and demographic dividends in developed and developing countries. In: Proceedings of the United Nations Expert Group Meeting on Social and Economic Implications of Changing Population Age Structure. United Nations publication, ESA/P/WP.201, pp 81-102

15. Urdal $H$ (2004) The devil in the demographics: the effect of youth bulges on domestic armed conflict, 1950-2000. The World Bank, Social Development Papers, Conflict Prevention \& Reconstruction, Paper No. 14, Washington DC

16. Pool I (2012) Demographic turbulence in the Arab World: implications for development policy. J Peacebuilding Dev 7(1):33-50

17. Amin M, Assaad R, Al-Baharna N (2012) After the Spring: economic transitions in the Arab world. Oxford University Press, Oxford

18. Gomez R, Lamb D (2013) Demographic origins of the great recession: implications for China. Chin World Econ 21(2):97-118

19. National Centre for Statistics and Information (NCSI) (2018) Statistical Year Book 2017. Sultanate of Oman, Ministry of National Economy, Muscat

20. Islam MM, Atsu SSD, Al-Qasmi MA (2011) Proximate determinants of declining fertility in Oman in the 1990s. Can Stud Popul 38:133-152

21. Islam MM (2017) Rapid fertility decline in Oman: understanding the role of proximate Determinants. Middle East Fert Soc J 22:275-284

22. Eberstadt, N. \& Shah, P. (2011). Fertility decline in the Muslim world: a veritable seachange, still curiously unnoticed, Working Paper Series on Development Policy, Number 7, American Enterprise Institute (AEI), USA, 2011.

23. Sulaiman AJM, Al-Ghassany A, Farid S (1992) Oman Child Health Survey 1988-89. Ministry of Health, Oman, Muscat

24. Sulaiman AJM, Al-Riyami A, Farid S (2000) Oman Family Health Survey 1995: Final Report. Ministry of Health, Muscat

25. Al-Riyami A, Afifi M, Al-Kharusi H, Morsi M (2000) National Health Survey, 2000. Vol. 2, Reproductive Health Survey. Ministry of Health, Muscat

26. Al-Riyami A, Abd-Elaty MA, Jaju S, Morsi M, Al-Kharusi H, Al-Shekaili W (2008) National Reproductive Health Survey. Ministry of Health, Muscat

27. United Nations, Department of Economic and Social Affairs, Population Division (2019) World Population Prospects: The 2019 Revision, custom data acquired via website. Available at http://population.un.org/wpp.

28. Mason A, Lee R, Michael Abrigo M, Lee SH (2017) Support ratios and demographic dividends: estimates for the world. Technical Paper No. 2017/ 1. Population Division, Department of Economic and Social Affairs, United Nations, New York 
29. Hinde A (1998) Demographic Methods. Arnold, London

30. Hobbs F (2004) Age and sex composition. In: Siegel JS, Swanson DA (eds) Methods and Materials of Demography. Elsevier Academic Press, New York

31. Mason A, Lee R (2007) Transfers, capital, and consumption over the demographic transition. In: Clark RL, Ogawa N, Mason A (eds) Population aging, intergenerational transfers and the macroeconomy. Edward Elgar, Cheltenham; Northampton, pp 128-162. https://doi.org/10.4337/ 9781847208583.00014

32. National Centre for Statistics and Information (NCSI) and UNICEF (2016) Multiple indicator cluster survey 2014, key findings. Ministry of National Economy Muscat, Sultanate of Oman

33. United Nations, Department of Economic and Social Affairs, Population Division (2019) World Urbanization Prospects: The 2018 Revision (ST/ESA/ SER.A/420). United Nations, New York

34. Shawky S (2001) Infant mortality in Arab countries: socioeconomic. Perinatal and economic factors. East Mediter Health J 7(6):956-965

35. Mirkin B (2010) Population levels, trends and policies in the Arab region: challenges and opportunities. Arab Human Development Report Research Paper Series. United Nations Development Programme, New York

36. Canning, D. (2011). The causes and consequences of the demographic transition. Program on the Global Demography of Aging (PGDA) Working Paper Series, Working Paper No. 79. http://www.hsph.harvard.edu/pgda/ working.htm.

37. Schultz TP (2009) How does family planning promote development? Evidence from a social experiment in Matlab, Bangladesh 1977-1996. Population Association of America, Dallas

38. Guiso L, Jappelli T, Pistaferri L (2002) An empirical analysis of earnings and employment risk. J Bus Econ Stat 20:1-13

39. Milligan K (2005) Lifecycle asset accumulation and allocation in Canada. Canad J Econ 38:1057-1106

40. Saxena P (2017) The nexus between components of population change and its impact on timing of opening and duration of reaping demographic dividend: can this period of economic miracle be augmented1? Empirical evidence from the Arab countries. Demog India 46(2):1-13

41. Lee R, Mason A (2006) What is the demographic dividend? Finance Dev 43: 3 https://www.imf.org/external/pubs/ft/fandd/2006/09/basics.htm

42. Crockett T (2014) Rethinking Arab Employment: A Systemic Approach for Resource-Endowed Economies. World Economic Forum, Geneva

\section{Publisher's Note}

Springer Nature remains neutral with regard to jurisdictional claims in published maps and institutional affiliations.

\section{Submit your manuscript to a SpringerOpen ${ }^{\circ}$ journal and benefit from:}

- Convenient online submission

- Rigorous peer review

- Open access: articles freely available online

- High visibility within the field

- Retaining the copyright to your article

Submit your next manuscript at $\boldsymbol{\nabla}$ springeropen.com 